\title{
Experimental investigation on influence of smoke venting velocity and vent height on mechanical smoke exhaust efficiency
}

\author{
Ji Jie ${ }^{\mathrm{a}}$, Li Kaiyuan ${ }^{\mathrm{b}}$, Zhong Wei ${ }^{\mathrm{c}, *}$, Huo Ran ${ }^{\mathrm{a}}$ \\ ${ }^{a}$ State Key Laboratory of Fire Science, University of Science and Technology of Chin, Hefei 230026, China; \\ ${ }^{\mathrm{b}}$ Department of Civil and Natural Resources Engineering, University of Canterbury, Christchurch 8140, New Zealand \\ ${ }^{\text {c }}$ School of chemical engineering, Zhengzhou University, Zhengzhou 450001, China
}

\begin{abstract}
:
A set of burning experiments were conducted to investigate the influence of smoke vent height and exhausting velocity on mechanical smoke exhausting efficiency. Results have shown that the smoke exhausting process becomes more efficient due to the increased smoke vent height and the decreased exhausting velocity, which eliminate the plug-holing issue with fewer disturbances on the smoke layer interface. For each certain exhausting velocity, there is a critical value of distance between the vent and the bottom of the smoke layer. When the distance is less than the critical value, the smoke exhausting is inefficient, and the efficiency decreases sharply as the distance decreases. Contrarily, when the distance is greater than the critical value, a good efficiency can be acquired and the exhausted smoke increased relatively slowly as the distance increases. A critical Froude number, proposed by Hinkley to predict the onset of plug-holing effect in gravity venting systems, was validated in the experiments. However, the experimental results indicate that in the tests without the plug-holing, the fresh air entrained due to smoke exhausting is up to $48 \%$ of the mechanical exhausting rate.
\end{abstract}

Keywords: smoke exhausting efficiency; smoke vent height; exhausting velocity; plug-holing 


\section{Introduction}

Statistics showed that smoke and toxic gases, such as carbon monoxide, are the most fatal hazard to the people in fires [1-3]. Therefore, when a fire occurs, it is very important to stop the smoke and toxic gases from spreading by natural or mechanical exhaust systems. As a result, the current building codes in China as well as lots of former studies on smoke management have mainly focused on the smoke exhausting rate and the proportion of fresh air within the smoke exhaust rate. However, except for the maximum limit of smoke exhausting velocity, no specific concern on the variation of exhausting velocity and smoke vent height is currently made in the building codes [4-7]. Actually, these two parameters are very important, especially to the spaces with less net height, such as the underground buildings (metro station, shopping mall, etc.) where a more efficient smoke exhausting is required. Usually a thin smoke layer is required for life safety in these places due to its height limit. Under this condition, if the smoke exhausting velocity is too large, the ambient fresh air beneath the smoke layer is easy to be directly (without mixing with smoke) or indirectly (mixing with smoke firstly) exhausted, resulting in smoke exhausting inefficiency. So, the study on these issues may benefit the current design of smoke management system and complement the current codes.

Recently, several former studies had been carried out to investigate the influence of the two factors on mechanical smoke exhausting efficiency. Shi et al.[8] experimentally studied the mechanical exhaust efficiency in compartment fire and claimed that when the exhausting vents were located near the smoke-air interface, larger disturbance occurred, under which a large amount of fresh air were entrained into upper smoke layer. Yi [9] conducted experiments to study the mechanical 
exhausting efficiency in a full-scale atirum and concluded that as the smoke layer below a smoke exhaust vent is relatively thin and the vent velocity is large enough, the entrained air significantly diluted the smoke layer and took a big proportion of the rated volume of smoke exhausting, which leaded to a poor mechanical smoke exhaust efficiency. A lot of other experiments were conducted by Lougheed et al [10] in a small scale atrium with a mechanical exhausting system. The results had shown that if there was a well-developed smoke layer below the exhausting inlets, the measured flow rate was comparable to the smoke generation rate, if not, the exhaust system would entrained a relatively large amount of fresh air, up to $75 \%$ of the mechanical exhausting capacity. Lougheed also claimed that the Froude number proposed by Hinkley [11] for "Plug-holing" (i.e. the fresh air is drawn directly into the smoke exhausting system from the lower layer) in natural smoke venting can be applied in mechanical smoke exhausting. Vauquelin [12] also noticed the plug-holing in some of the transverse smoke exhausting experiments in a small scale tunnel with less net height. His conclusion was that in the cases with plug-holing, the smoke exhausting efficiency had strongly decreased. However, in these former studies, delicate quantitative analyses on how the exhausting velocity and smoke vent height influence the mechanical smoke exhausting efficiency has rarely been addressed. The disturbance of mechanical smoke exhausting on the smoke-air interface, which causes different amount of fresh air exhausted directly and indirectly, leads to different smoke exhausting efficiencies, has rarely been discussed. Actually, the influence in the enclosures with less net height is more significant, due to a thin smoke layer required for life safety. The Hinkley's model also needs quantitatively validation for mechanical smoke exhausting system, especially to the buildings with less net height.

In order to investigate the influence of these two factors on smoke exhausting 
efficiency, a set of experiments were conducted. The CO concentration in the exhaust duct, the smoke layer temperature and the smoke spilling rate are experimentally measured. Meanwhile, the values predicted by Hinkley’s model are compared with experimental results and some suggestions are proposed to achieve a excellent smoke exhausting efficiency.

\section{Theoretically analysis}

The smoke exhausting process with a smoke layer below an exhausting vent is shown in Figure 1 . As shown in the figure, $\dot{m}_{e}$ is the smoke exhausting rate, $\dot{m}_{s}$ is the smoke proportion of the exhausting rate, $\dot{m}_{a}$ is the entrained fresh air due to the mixture with smoke layer, $\dot{m}_{p}$ is the exhausted fresh air drawn directly from the lower layer due to the plug-holing effect. The correlation of these variables can be expressed as

$$
\dot{m}_{e}=\dot{m}_{s}+C \dot{m}_{a}+\dot{m}_{p}
$$

where, $C$ is a coefficient which is between 0 and 1 . Theoretically, less $C \dot{m}_{a}$ and $\dot{m}_{p}$ lead to better smoke exhausting efficiency. If the value of $\dot{m}_{p}$ does not equal to zero, plug-holing occurs, which might be avoided by ensuring the smoke layer below smoke vent to be thick enough and an appropriate exhausting velocity.

As shown in Equation (1), it is implied that only part of the mixed air, $C \dot{m}_{a}$, is exhausted by smoke vent, and the rest of it $\left((1-C) \dot{m}_{a}\right)$ stays in the smoke layer and keeps spreading along. Therefore, the increase of smoke under mechanical smoke exhausting can be determined by

$$
\dot{m}=\dot{m}_{f}-\dot{m}_{e}+\dot{m}_{a}+\dot{m}_{p}
$$


where, $\dot{m}_{f}$ is the mass flow rate of plume, as shown in the Figure 1 , which is the smoke induced solely by a fire (to make a distinction to the increase of smoke due to the entrained fresh air induced by mechanical smoke exhausting) and can be estimated by the plume entrainment models in literatures [14-16]. Under an ideal smoke controlling condition, $\dot{m}_{a}$ and $\dot{m}_{p}$ should be zero, and $\dot{m}_{e}$ should equal to $\dot{m}_{f}$. Therefore, $\dot{m}$ equals to zero so that the smoke exhausting operates at the maximum efficiency under which the smoke generated by the plume is totally exhausted without any fresh air mixed in the smoke layer or entering into the vent.

Hinkley has proposed a modified Froude number to determine the occurrence of plug-holing in natural venting systems [11], which is

$$
F=\frac{u_{e} A}{\left(g \Delta T / T_{0}\right)^{1 / 2} d^{5 / 2}}
$$

where, $u_{e}$ is the flow velocity at the smoke vent $(\mathrm{m} / \mathrm{s}), A$ is the area of the smoke vent $\left(\mathrm{m}^{2}\right), \quad d \quad$ is the thickness of smoke layer $(\mathrm{m}), \Delta T$ is the average temperature rise of the smoke layer $(\mathrm{K}), T_{0}$ is the ambient temperature $(\mathrm{K})$, and $g$ is the gravity acceleration $\left(\mathrm{m} / \mathrm{s}^{2}\right)$. The physical meaning of $\mathrm{F}$ in Equation (3) is the ratio of the inertia force to the gravity force which is relevant to the buoyant flows associated with fires. For the occurrence of the plug-holing, there is a critical Froude number named as $F_{\text {critical }}$. It can be inferred that when the Froude number under certain condition is greater than $F_{\text {critical }}$, fresh air in the lower layer is drawn directly into the mechanical vent. Former studies [13] have shown that $F_{\text {critical }}$ of 1.5 is applicable for vents closed to the center of the smoke reservoir and 1.1 is suitable to the vents near the reservoir sides [12]. Lougheed concluded that the Froude number can be used to determine the plug-holing in mechanical smoke exhausting atria [10]. However, a further quantitatively validation is expected. 


\section{Experiments}

The experimental set up is shown in Figure 2. It constitutes of two parts, the burning cabin and the smoke filling cabin, as shown in Figure 2. Pool fires are burned in the burning cabin to generate an initial stable smoke layer in the upper part of the smoke filling cabin. The burning cabin is $4 \mathrm{~m}$ long, $2 \mathrm{~m}$ wide and $2.5 \mathrm{~m}$ high. Six make-up air intakes with a length of $0.8 \mathrm{~m}$ and a height of $0.4 \mathrm{~m}$ are settled on both sides of the cabin. The smoke filling cabin is a cube with a length of $4.2 \mathrm{~m}$, a width of $4.2 \mathrm{~m}$ and a height of $4 \mathrm{~m}$. Smoke curtains, with heights of $1.0 \mathrm{~m}$ on the south side and 2.0m on the other three sides, are installed below the top of the cabin to maintain an initial stable smoke layer. As shown in Figure 2, a $30 \mathrm{~cm} \times 30 \mathrm{~cm}$ smoke exhausting vent is located at the ceiling of the smoke filling cabin. Five pieces of short mountable ducts with a size of $30 \mathrm{~cm} \times 30 \mathrm{~cm} \times 20 \mathrm{~cm}$ (depth) were used to vary the vent height from $3.0 \mathrm{~m}$ to $4.0 \mathrm{~m}$ with an interval of $20 \mathrm{~cm}$. The rate of smoke exhausting is adjustable within the range of $0-5000 \mathrm{~m}^{3} / \mathrm{h}$. As mentioned above, the mechanical fan may suck a mixture of the smoke induced solely by the fire and the fresh air due to the disturbance of mechanical smoke exhausting on the smoke-air interface.

As shown in Figure 2, two set of thermocouples were used to measure the temperature in the smoke filling cabin and the spilling smoke from the south side respectively. The thermocouples were setup with $0.25 \mathrm{~m}$ spacing and the highest ones were $3 \mathrm{~cm}$ below ceiling. Two gauges with an accuracy of centimeter were installed between the bottom of the smoke curtain and ground, to measure the height of the smoke. Two KANOMAX hot-wire anemometers were located below the smoke curtain on the south side, to measure the smoke spilling thickness and velocity 
respectively. A Testo350XL gas analyzer with 3 CO sensors was used. The sensors were put in the exhausting duct, below the south side smoke curtain and in the smoke filling cabin to measure CO concentration at different places.

A total of 19 tests were conducted with a $30 \mathrm{~cm} \times 30 \mathrm{~cm}$ square pool fire. The experimental data have been shown in Table 1. Gasoline was used as the fuel. Heat release rate of the pool fire is determined by the mass loss rate measured by an electronic balance and the heat value of the gasoline which is taken to be $46000 \mathrm{~kJ} / \mathrm{kg}$. Factor of the burning efficiency is 0.8 [9]. As a result, the average steady state heat release rate in the experiments is $120 \mathrm{~kW}$.

In the experiments, all devices were operated for measurement at the time of ignition. Several seconds later, a thick black layer formed in the burning cabin and then the smoke flowed into the smoke filling cabin. At about 22s after the ignition, the smoke reached the center of the smoke filling cabin where a thermocouple tree was located, and gradually filled the hood until the smoke spilled out from the shortest curtain on the south side. At about 120s after ignition, the smoke flow reached a relatively steady state under which the depth of smoke layer was monitored with the gauges. In the tests with smoke exhausting, the mechanical fan was operated at 180s.

\section{Results and Discussion}

\subsection{Experimental results}

The experimental data, including the smoke layer temperature and CO concentration in the exhaust duct, are presented ahead of smoke exhaust efficiency discussion.

The temperatures measured in Test 1 and Test 2 are presented in Figure 3. The 
recording interval for the thermocouples is $0.5 \mathrm{~s}$. The uncertainties for these temperature measurements were estimated to be less than $1^{\circ} \mathrm{C}$ [17]. It can be found in Figure 3(a) that the temperature in the smoke filling cabin started to increase at about 22s, and remained a relatively steady state after 120 s, The steady state lasted for 300 s in Test 1 which was running without smoke exhausting. In the tests with smoke exhausting, the mechanical fan was operated at 180s. Then the smoke temperature dropped at this moment and reached the other steady state at 270s as shown in Figure 1(b). The fuel was running out at around 400s. The CO concentration measured in smoke exhausting duct in one test is shown in Figure 4 in which a steady state phase is found after 270s. The smoke temperature and the CO concentration were averaged from the steady state and used in following sections.

\subsection{Smoke spilling}

The smoke started to spill out from the bottom edge of south smoke curtain after the cabin was filled up. The thickness of the spilling smoke became stable when the smoke temperature stabilized after 120s. The thickness is measured by the two gauges and recorded every 10s. Then the time averaged value for the steady state was made in all tests and plotted in Figure 5. Consequently, thickness of the smoke layer below the vent is easily calculated by considering the smoke curtain height and the vent height.

As shown in Figure 5, the smoke spilling thickness is $0.295 \mathrm{~m}$ in Test 1 without smoke exhausting, which is higher than the ones in the smoke exhausting tests. Under certain exhausting velocity, the thickness of spilling smoke decreases as the vent height increases. When the vent height increases from $3.0 \mathrm{~m}$ to $3.2 \mathrm{~m}$ for all three 
exhausting velocities, the smoke spilling thickness has strongly decreased. However, the vent height becomes less effective as it increases, which leads to the change of spilling thicknesses becomes smaller and eventually tends to be zero. For instance, under $10 \mathrm{~m} / \mathrm{s}$ exhausting velocity, the spilling thickness decreases $0.05 \mathrm{~m}$ as the vent height increases from $3.0 \mathrm{~m}$ to $3.2 \mathrm{~m}$, but remains approximately constant when the smoke vent moves up from $3.8 \mathrm{~m}$ to $4.0 \mathrm{~m}$.

Under certain vent height, the change of smoke spilling thicknesses with different exhausting velocities is more complicated. As the vent is relatively low, at the height of $3.0 \mathrm{~m}$ and $3.2 \mathrm{~m}$, the spilling smoke becomes thicker as the exhausting velocity increases. However, when the smoke vent is relatively high, contrary results are found. Actually, the different extents of disturbance of mechanical smoke exhausting on the smoke-air interface, which causes different amount of fresh air exhausted directly and indirectly, lead to different smoke exhaust efficiencies. At the tests with a lower vent, the smoke layer below the vent is relatively thin so that a higher exhausting velocity is much easier to cause more disturbances on the smoke-air interface. Therefore more fresh air is entrained into smoke layer, which increases the smoke layer thickness. Part of air entrainment $\left(C \dot{m}_{a}\right)$ is exhausted while the rest of it stays in the smoke layer. On the other hand, there is some fresh air exhausted directly by the vent due to the plug-holing effect, which also reduces the exhausting efficiency. As a result, the smaller exhausting process becomes more effective as the exhausting velocity decreases. As the vent moves up, smoke layer below the vent becomes thicker so that the disturbance of smoke exhausting is reduced. The plug-holing effect is then avoided and therefore the air entrainment is reduced. Under this condition, more smoke is exhausted as the exhausting velocity increases. As a result, thickness of the spilling smoke decreases. As the vent height increases, the influence of smoke 
exhausting on the smoke-air interface become less effective till ignorable since the thick smoke layer prevents the fresh air being mixed in. Therefore, the smoke exhausting efficiency becomes stable, which leads to the curves in Figure 5 tend to be flat with increasing of vent height.

Based on smoke spilling thicknesses and velocities, the volumetric flow rates of smoke spilling can be calculated, as shown in Figure 6, and thus the comparison of the mechanical exhausting rate against the decrease of the volumetric spilling flow rates is shown in Figure 7. As shown in Figure 6, for all exhausting velocities, the volumetric flow rate of spilling smoke decreases as the velocities increase. Under certain vent height, the volumetric flow rate decreases as the exhausting velocity increases. In tests with vent height of $3.0 \mathrm{~m}$ and $3.2 \mathrm{~m}$, even though the spilling smoke with a higher exhausting velocity is thicker, the spilling velocity is lower. Consequently, the volumetric flow rates of spilling smoke in tests with higher exhausting velocities are less than those with lower velocities. For tests with $3.8 \mathrm{~m}$ and $4.0 \mathrm{~m}$ high vent, the volumetric flow rates of spilling smoke under the $10 \mathrm{~m} / \mathrm{s}$ exhausting velocity are only half of those under $4 \mathrm{~m} / \mathrm{s}$ exhausting velocity, as shown in Figure 6.

In theory, the decreases of spilling smoke flow should equal to the volumetric smoke exhausting rate since the impact of the fresh air should not exist in an ideal smoke exhausting process. One of our experiments objectives was to figure out the conditions under which the smoke exhausting system was operating at maximum efficiency. However, in terms of the experimental results, $\dot{m}_{a}$ always exists, more or less. Therefore, even for Test 19 with highest vent and lowest exhausting velocity, the decreasing volumetric flow rate of spilling smoke is still lower than volumetric exhausting rate. Figure 7 indicates that the ratio of mechanical exhaust rate to the 
decreasing volumetric flow rate of spilling smoke ranged from 1.4:1 to 3.6:1. And with decreasing of the vent height, the ratio increases, indicating more fresh air entrained into smoke.

\subsection{CO concentration}

The CO concentrations measured in the cabin and the exhaust duct is used to provide further information on the fresh air entrainment, i.e. $C \dot{m}_{a}$. The average CO concentration in smoke layer in Test 1 is 23ppm. The CO concentration averaged in the exhausting duct in Test 2-19 are shown in Figure 8. For optimizing a smoke exhausting process, the disturbance on the smoke-air interface by smoke exhausting should be reduced to as little as possible. From this point of view, the CO concentration measured in the duct should be comparable to 23ppm. In tests with vent height of $3.6 \mathrm{~m}-4 \mathrm{~m}$ and a exhausting velocity of $4 \mathrm{~m} / \mathrm{s}$, the CO concentration is $20 \mathrm{ppm}$, which is the maximum value got from the experiments. There is little fresh air being entrained into the duct during these tests and the exhausted smoke is mainly from the smoke layer in the cabin. For tests with higher exhausting velocity and thin smoke layer below the vent, there is a significant decrease of CO concentration in the duct, as shown in Figure 5, which indicates that the smoke was significantly diluted by air entrained from the lower layer. In Test 2 with 3.0m high vent and 10m/s exhausting velocity, the $\mathrm{CO}$ concentration eventually decreased to 11ppm due to the large amount of fresh air exhausted into the duct, in other words, actually less than half of the exhausting rate was used. These results are consistent with previous data. It can be found in the figure that the maximum dilution multiple indicated from $\mathrm{CO}$ data is 
approximately 2.09. It is also can be seen that under certain smoke exhausting velocity, there is a transition zone for vent height. In tests with vent lower than the transition zone, the smoke exhausting efficiency decreased significantly as shown in Figure 5 . Under $10 \mathrm{~m} / \mathrm{s}, 7 \mathrm{~m} / \mathrm{s}$ and $4 \mathrm{~m} / \mathrm{s}$ exhausting velocities, the transition zones are 3.4m-3.6m, 3.6m-3.8m and 3.6m-3.8m, respectively.

\subsection{Comparison with Hinkley`s model}

As mentioned above, if the vent were located well above a critical height, the vent height would have little impact on the exhausting efficiency. On the contrary, the smoke exhausting efficiency decreases as the smoke vent moves downward. According to the former studies [10-13], the plug-holing effect causes the significant decrease of smoke exhausting efficiency, and in the natural venting systems, the critical conditions of this effect is determined by Equation (1). However, Hinkley [11] defines Equation (1) in terms of the smoke depth below the vents which has been assumed to be located at the ceiling. In the following analysis, the smoke depth in Equation (1) is replaced by the distance between the exhausting vent and the smoke-air interface. Using Equation (1), the Froude numbers of all tests is obtained, as shown in Figure 9, and the plug-holing effect is predicted. In the calculation, $\Delta T$ were taken as the average smoke temperature below the exhausting vent.

Comparing Figure 9 with Figure 8, it can be seen that the Froude numbers in the tests with significantly low smoke exhausting efficiency, i.e. under the transition zone in Figure 8, are all greater than the critical value for determining the onset of plug-holing, 1.1. And, the Froude numbers in tests with relatively higher smoke exhausting efficiency are all less than 1.1. There is a good agreement between model prediction and the experimental results. The model could be used as a design guide 
for engineers dealing with the plug-holing effect in a smoke management system. However, it should be pointed out that the Hinkley's equation can only be used to predict the significant decrease of smoke exhausting efficiency, and can’t account for the influence of disturbances at the smoke layer interface on the smoke exhausting effect.

As shown in Figure 7, the Hinkley's model is not enough for mechanical smoke exhausting system design. The tests without the plug-holing (Test 13-19) are discussed to evaluate the influence of the fresh air entrained due to the mixture with smoke layer on the smoke exhausting efficiency. In these tests, $\dot{m}_{p}$ equals to zero as there is not plug-holing effect. In terms of Equation (2) and Figure 7, the volumetric flow rates of the entrained fresh air due to the mixture with smoke layer, $\dot{m}_{a}$, is calculated. Meanwhile, the proportion of the entrained air, which is exhausted by the smoke vent, is determined by comparing the $\mathrm{CO}$ concentration in Figure 8 to the original value of 23ppm which has been measured in test 1 . Therefore, a value of $C$ is acquired by comparing the exhausted proportion with the amount of entrained air. As shown in Figure 3(a), the highest average temperature of smoke layer is calculated to be $294 \mathrm{~K}$. Based on which, a ratio of the ambient temperature over the smoke temperature is calculated to be $95 \%$ which means the smoke temperature is very close to the ambient temperature. As a result, the density difference between the smoke and the fresh air, which actually leads to a variation of smoke volume, is ignored in the calculation. The results are shown in Table 2. It can be seen that about half of the fresh air entrained was exhausted by the mechanical fan and the rest stayed in the smoke layer and kept spreading along. The fresh air exhausted is calculated up to $48 \%$ (in Test 14) of the mechanical exhausting rate. Therefore, in order to achieve an excellent smoke exhausting effect, the amount of fresh air entrained due to smoke 
exhausting, $m_{a}$, should be reduced to as less as possible.

\section{Conclusions}

In this study, a set of burning experiments was conducted to investigate the effect of smoke vent height and exhausting velocity on mechanical smoke exhausting efficiency. A high smoke vent as well as a low exhausting velocity can prevent the plug-holing effect and reduce the disturbance acted on the smoke layer interface, which eventually lead to an efficient smoke exhausting process. On the other hand, a low smoke vent with a large exhausting velocity causes an inefficient smoke exhausting process. Under certain exhausting velocity, there was a critical vent height under which the smoke exhaust efficiency strongly decreases as the vent height decreases. On the contrary, the exhausting efficiency won't change much as the vent height increases, which has been considered as the maximum efficiency under this velocity. A Froude number, proposed by Hinkley to predict the plug-holing effect in natural venting systems, is validated. The critical Froude number for plug-holing effect predicted by Hinkley's model agrees well with the experimental results, which indicates that Hinkley's model can be used as a basis criterion for designing the mechanical smoke exhausting system.

Future work will focus on fire sources with higher heat release rate and the accurate determination of related parameters. A lot more experiments will be conducted to investigate the mechanism of the air entrainment process. 


\section{ACKNOWLEDGEMENT}

This work was supported by Natural Science Foundation of China (NSFC) under Grant No. 50904055. Kai-Yuan Li is currently the Arup Fire Post-doctorate Fellow at the University of Canterbury. 


\section{Nomenclature}

A area of the smoke vent $\left(\mathrm{m}^{2}\right)$

$C_{1}$ coefficient

$d \quad$ thickness of smoke layer (m)

F Froude number

$g$ is the gravity acceleration $\left(\mathrm{m} / \mathrm{s}^{2}\right)$

$\dot{m}_{a}$ mass flow rate of entrained fresh air due to the mixture with smoke layer $\left(\mathrm{kgs}^{-1}\right)$

$\dot{m}_{e}$ smoke exhausting rate $\left(\mathrm{kgs}^{-1}\right)$

$\dot{m}_{f}$ mass flow rate of fire plume $\left(\mathrm{kgs}^{-1}\right)$

$\dot{m}_{s}$ mass flow rate of smoke proportion of the exhausting rate $\left(\mathrm{kgs}^{-1}\right)$

$\dot{m}_{p}$ mass flow rate of exhausted fresh air drawn directly from the lower layer $\left(\mathrm{kgs}^{-1}\right)$

$\Delta T$ average temperature rise of the smoke layer (K)

$T_{0}$ ambient temperature (K)

$u_{e}$ flow velocity $(\mathrm{m} / \mathrm{s})$ 
References

[1] J. Hietaniemi, R. Kallonen, E. Mikkola, Burning Characteristics of Selected Substances: Production of Heat, Smoke and Chemical Species, Fire Mater., 23(1999) 171-185.

[2] V. Babrauskas, R.G. Gann, B.C. Levin, M. Paabo, R.H. Harris, R.D. Peacock, S. Yasa, A Methodology for Obtaining and Using Toxic Potency Data for Fire Hazard Analysis, Fire Saf. J., 31(1998) 345-58.

[3] R. Besserre, P. Delort, Recent Studies Prove that the Main Cause Of Death During Urban Fires is Poisoning by Smoke, Urgence Medicales, 16(1997) 77-80.

[4] The Ministry of Construction P.R.China, Code for Design of Subway (GB 50157), 2003 edition.

[5] The Ministry of Public Security of P.R.China, Code for Fire Protection Design of Buildings (GBJ 16-87), 2001 edition.

[6] The Ministry of Public Security of P.R.China, Code for Fire Protection Design of Tall Buildings (GB50045-95), 2001 edition.

[7] The Ministry of Public Security of P.R.China, Code for Fire Protection Design of Civil Air Defence Works, 2001 edition.

[8] C.L. Shi, Y.Z. Li, R. Huo, Modeling and Experimental Studies on Mechanical Exhaust Efficiency in Compartment Fire, Combust. Sci. Technol., 9(2003) 546-550.

[9] L. Yi, Study on Smoke Movement and Management in Atrium Building. PhD dissertation, University of Science and Technology of China, Hefei, Anhui, China, 2005.

[10] G.D. Lougheed, G.V. Hadjisophocleous, The Smoke Hazard from a Fire in High Spaces, ASHRAE Trans., 107(2001) 34-38.

[11] L.Y. Cooper, Smoke and heat venting, Chapter 3-9. SFPE Handbook of Fire 
Protection Engineering (3rd ed.), Society of Fire Protection Engineers and National Fire Protection Association, Boston, MA, USA, 2002.

[12] O. Vauquelin, Experimental Simulations of Fire-Induced Smoke Control in Tunnels Using an “Air-Helium Reduced Scale Model”: Principle, Limitations, Results and Future, Tunn. Undergr. Sp. Tech., 23 (2008) 171-178.

[13] H.P. Morgan, J.P. Gardiner, Design Principles for Smoke Ventilation in Enclosed Shopping Centres, BR186, Building Research Establishment, Garston, U.K, 1990.

[14] B.J. McCaffrey, Momentum Implications for Buoyant Diffusion Flames. Combust. Flame, 52(1983) 149-167.

[15] G. Heskestad, Engineering Relations for Fire Plumes, Fire Saf. J., 7(1984) 25-32.

[16] E. E. Zukoski, T. Kubota, B. Cegeten, Entrainment in Fire Plumes. Fire Saf. J., 3(1980) 107-121.

[17] L.H. Hu, Y.Z. Li, R. Huo, L. Yi, W.K. Chow, Full-scale experimental studies on mechanical smoke exhaust efficiency in an underground corridor, Build. Environ., 41(2006) 1622-1630. 
Table 1 Summary of tests

\begin{tabular}{cccccc}
\hline Test No. & $\begin{array}{c}\text { HRR } \\
(\mathrm{kW})\end{array}$ & $\begin{array}{c}\text { Ambient } \\
\text { temperature }(\mathrm{K})\end{array}$ & $\begin{array}{c}\text { Vent height } \\
(\mathrm{m})\end{array}$ & $\begin{array}{c}\text { Vent velocity } \\
(\mathrm{m} / \mathrm{s})\end{array}$ & $\begin{array}{c}\text { Volume rate of } \\
\text { smoke exhaust }(\mathrm{m} 3 / \mathrm{s})\end{array}$ \\
\hline 1 & 120 & 279.8 & 3 & 0 & 0 \\
2 & 120 & 280.3 & 3 & 10 & 0.9 \\
3 & 120 & 279.8 & 3 & 7 & 0.63 \\
4 & 120 & 279.8 & 3 & 4 & 0.36 \\
5 & 120 & 279.5 & 3.2 & 10 & 0.9 \\
6 & 120 & 279.8 & 3.2 & 7 & 0.63 \\
7 & 120 & 279.5 & 3.2 & 4 & 0.36 \\
8 & 120 & 279.5 & 3.4 & 10 & 0.9 \\
9 & 120 & 279.5 & 3.4 & 7 & 0.63 \\
10 & 120 & 280 & 3.4 & 4 & 0.36 \\
11 & 120 & 280 & 3.6 & 10 & 0.9 \\
12 & 120 & 280 & 3.6 & 7 & 0.63 \\
13 & 120 & 280 & 3.6 & 4 & 0.36 \\
14 & 120 & 280.3 & 3.8 & 10 & 0.9 \\
15 & 120 & 280 & 3.8 & 7 & 0.63 \\
16 & 120 & 280.5 & 3.8 & 4 & 0.36 \\
17 & 120 & 280 & 4.0 & 10 & 0.9 \\
18 & 120 & 281 & 4.0 & 7 & 0.63 \\
19 & 120 & 280.4 & 4.0 & 4 & 0.36 \\
\hline
\end{tabular}

Table 2 Volume rate of entrained fresh air and $C$

\begin{tabular}{cccccc}
\hline $\begin{array}{c}\text { Test } \\
\text { No. }\end{array}$ & $\begin{array}{c}\text { Vent height } \\
(\mathrm{m})\end{array}$ & $\begin{array}{c}\text { Vent velocity } \\
(\mathrm{m} / \mathrm{s})\end{array}$ & $\begin{array}{c}\text { Volume rate of } \\
\text { smoke exhaust }\left(\mathrm{m}^{3} / \mathrm{s}\right)\end{array}$ & $\begin{array}{c}\text { Volume rate of entrained } \\
\text { fresh air }\left(\mathrm{m}^{3} / \mathrm{s}\right)\end{array}$ & $\boldsymbol{C}$ \\
\hline 13 & 3.6 & 4 & 0.36 & 0.12 & 0.6 \\
14 & 3.8 & 10 & 0.9 & 0.43 & 0.46 \\
15 & 3.8 & 7 & 0.63 & 0.2 & 0.55 \\
16 & 3.8 & 4 & 0.36 & 0.13 & 0.57 \\
17 & 4.0 & 10 & 0.9 & 0.42 & 0.47 \\
18 & 4.0 & 7 & 0.63 & 0.21 & 0.52 \\
19 & 4.0 & 4 & 0.36 & 0.11 & 0.64 \\
\hline
\end{tabular}




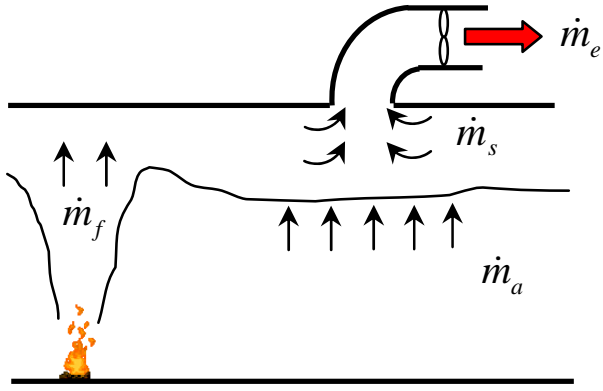

(a)

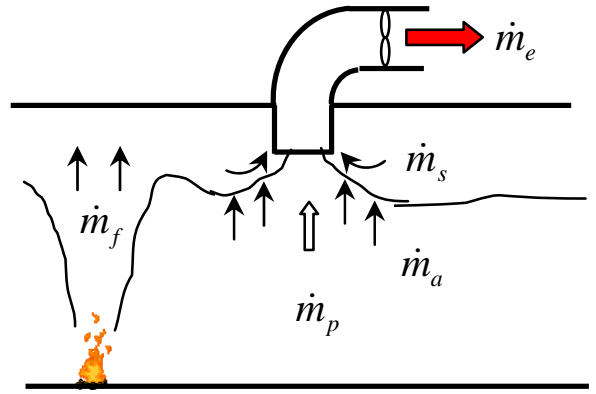

(b)

Fig.1 Flow field below exhaust vent

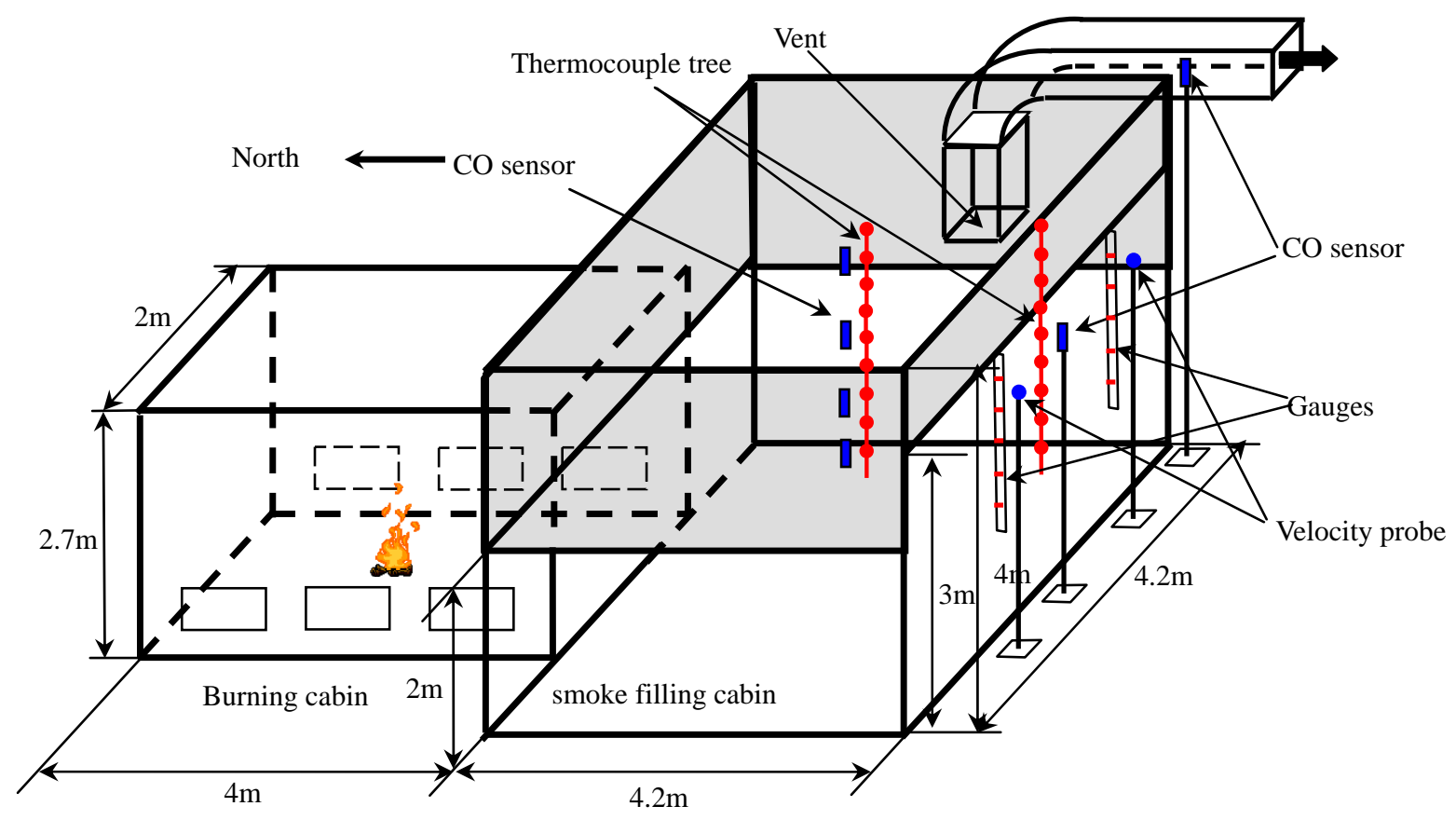

Figure 2 Schematic view of experimental apparatus 


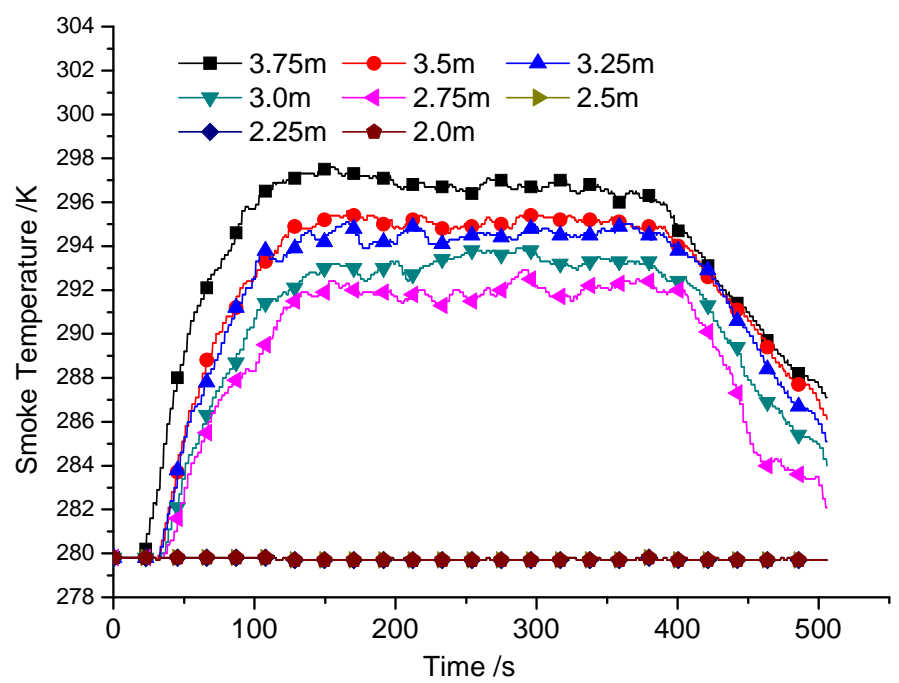

(a)

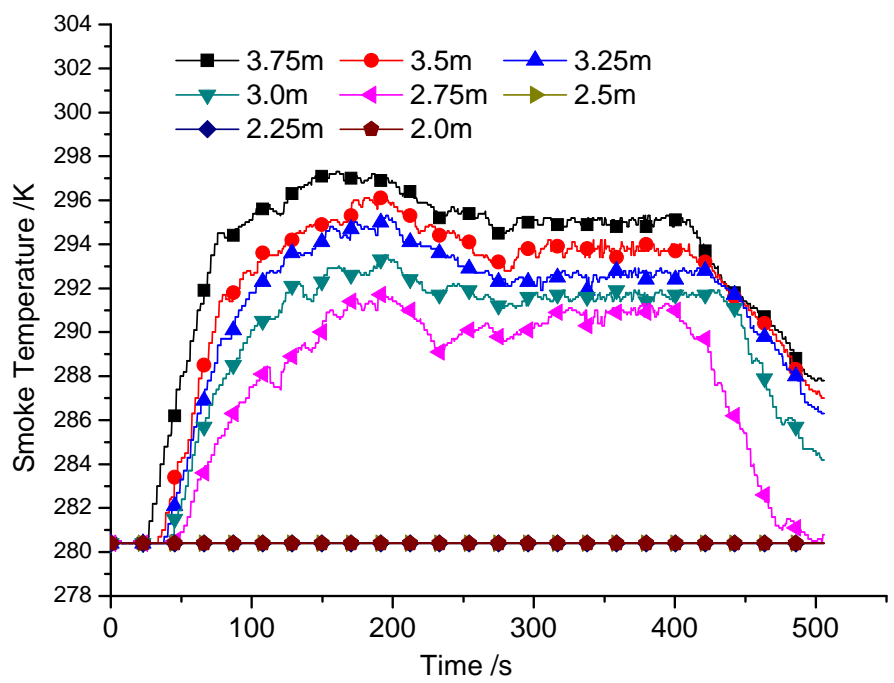

(b)

Fig.3 Temperature curves measured under the ceiling in smoke filling cabin: (a) test 1 without smoke exhausting; (b) test 2 with smoke exhausting 


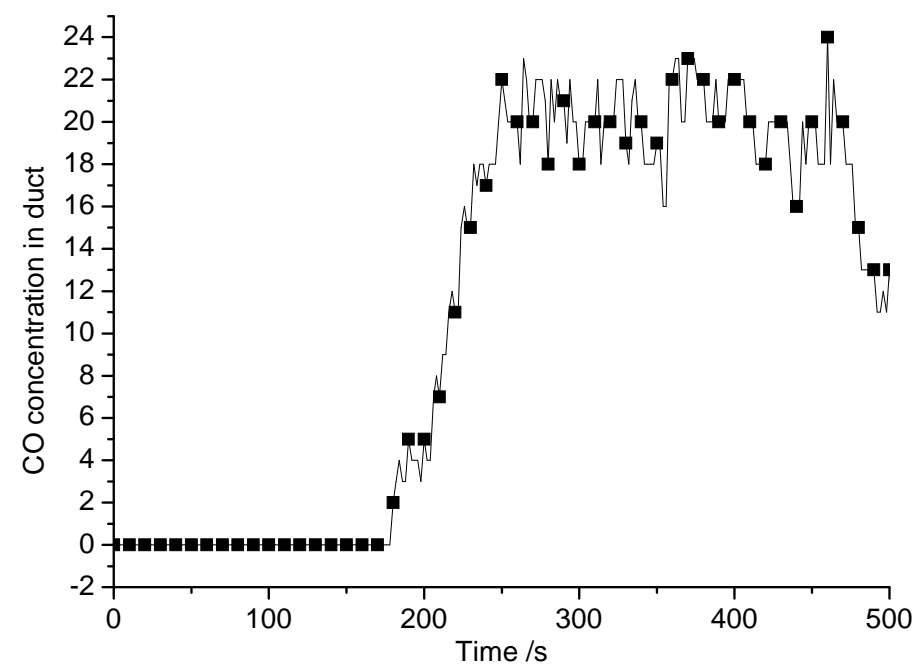

Figure 4 CO concentration measured in smoke exhausting duct in test 13

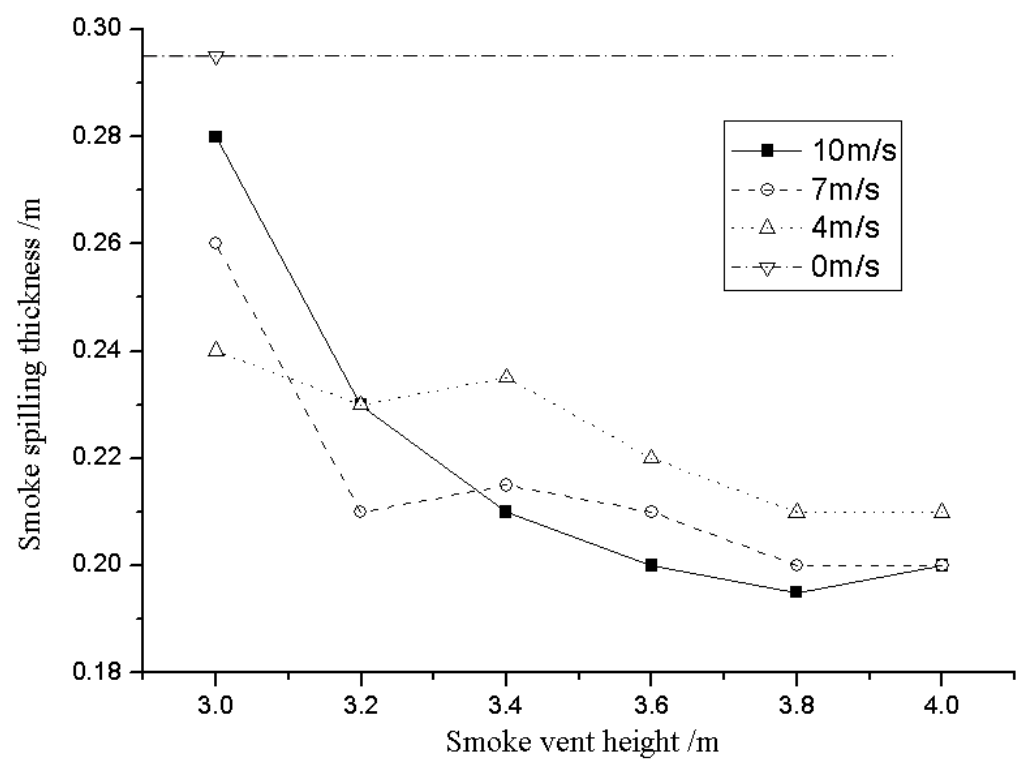

Figure 5 Smoke spilling thicknesses for all tests 


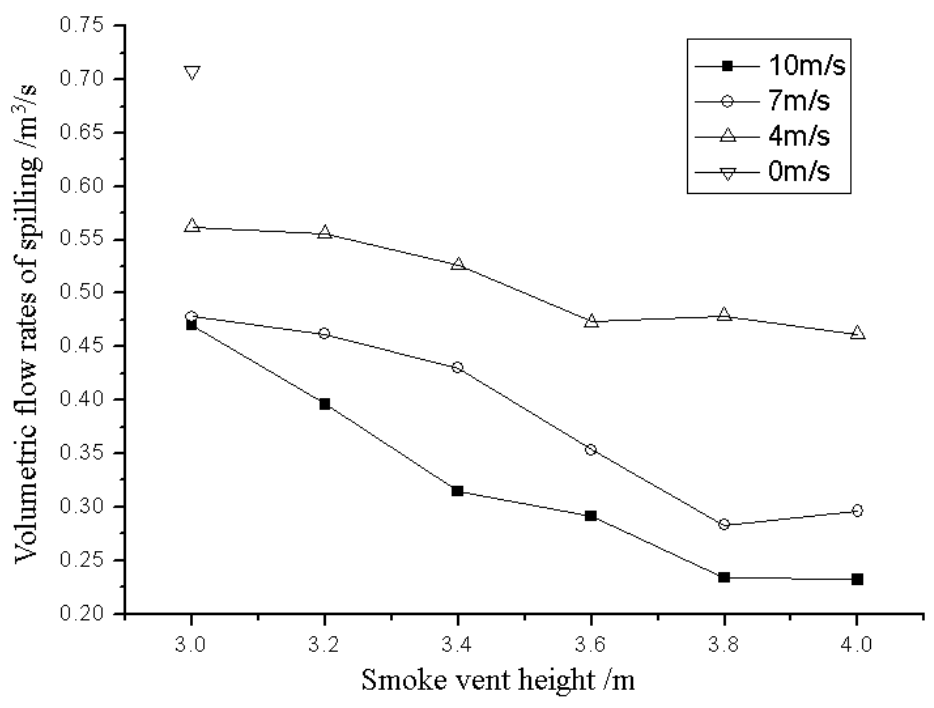

Figure 6 Volumetric flow rates of smoke spilling for all tests

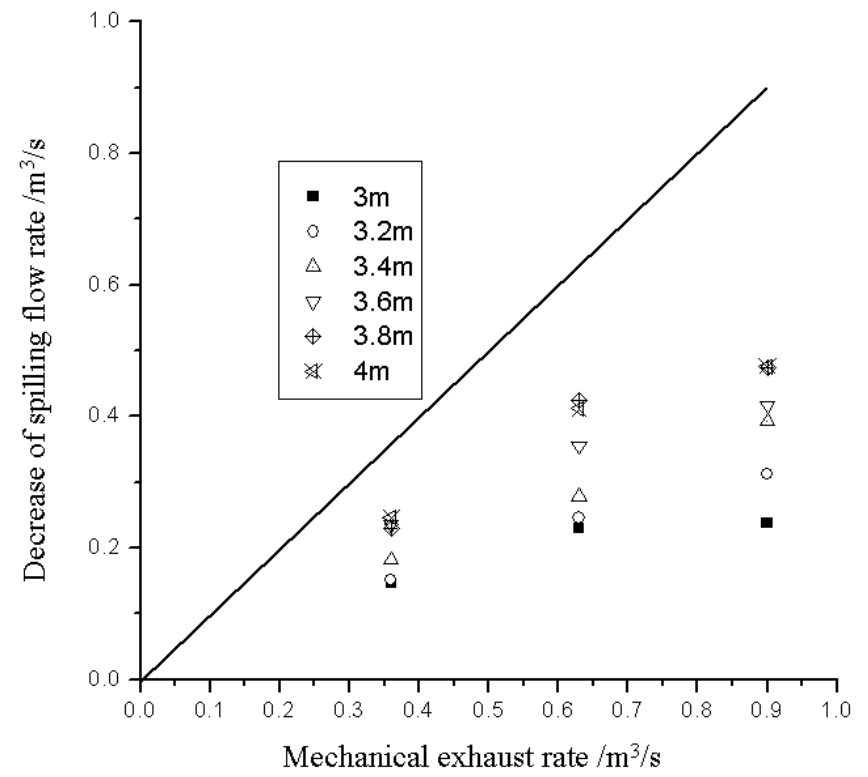

Figure 7 Mechanical exhaust rates vs. decreased volumetric flow rates of smoke spilling for all tests 


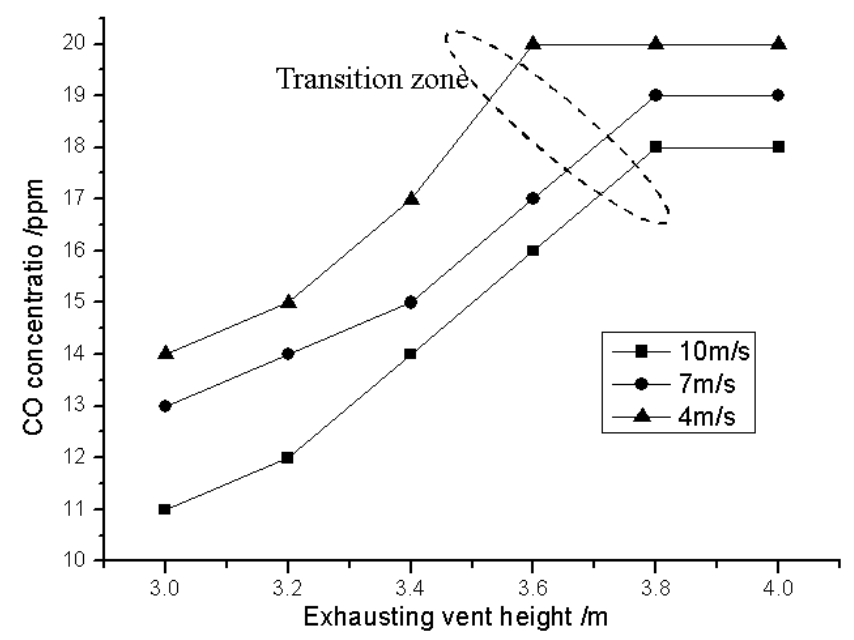

Figure $8 \mathrm{CO}$ concentration in exhaust duct in test 2-19

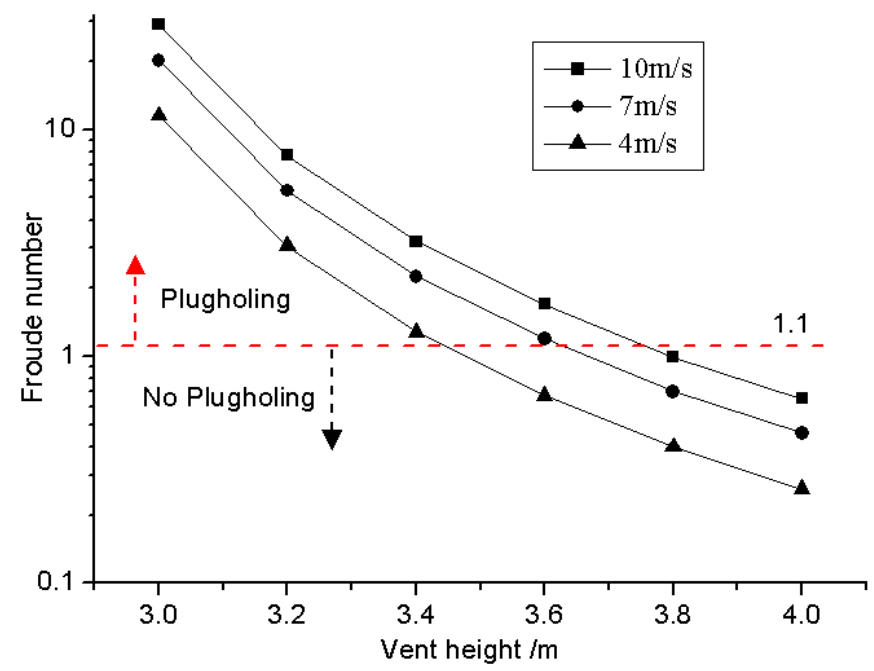

Figure 9 Comparison between Hinkley's model and experimental results 